\title{
As revistas literárias no romantismo francês: a ilustração
}

\section{Celina Maria Moreira de Mello}

Resumo: Serão comentados, aqui, alguns aspectos das relações entre o mundo da imprensa e o campo literário e político, no romantismo francês, enfatizando o impacto político e a liberdade do folhetim crítico, em face da censura. Serão, a seguir, apresentadas quatro revistas literárias que acolheram os autores do romantismo. Finalmente, será destacada a presença da ilustração. Palavras-chave: folhetim crítico, romantismo francês, ilustração.

Abstract: We will first examine some aspects of the relationships existing between the world of press and the literary and political field, in French Romanticism, emphasizing the political impact and liberty of feuilleton critics towards censorship. Then, we will present four literary reviews in which romantic authors were invited to publish their writings. Finally, illustrations presence will be especially commented. Keywords: feuilleton critics, French Romanticism, illustrations. 


\section{Introdução}

Este ensaio vincula-se a um trabalho de pesquisa que problematiza o objeto literário, nas relações entre a literatura francesa e a pintura, e mais recentemente a gravura, construindo a noção heurística de espaço-histórico romântico, em uma perspectiva discursiva ${ }^{1}$ e sócio-histórica. ${ }^{2}$ A leitura do literário é redimensionada em sua inserção histórica, na perspectiva foucaultiana de formação discursiva, ${ }^{3}$ que aproximo da longue durée de Braudel e das abordagens da Nova História. ${ }^{4}$ Levo em conta as práticas textuais em seu momento histórico, recusando, ao definir romantismo, abordagens de cunho linear, portadoras da ideia de progresso, que configuraram a tradição de história literária francesa marcada pelo positivismo e a herança lansoniana.

Serão comentados, aqui, alguns aspectos das relações entre o mundo da imprensa e o campo literário e político, no romantismo francês, ${ }^{5}$ destacando, em primeiro lugar, o impacto político e a liberdade em face da censura do folhetim crítico. ${ }^{6}$ Uma breve retrospectiva da história do folhetim no Journal des Débats, entre 1799 e 1808, constitui uma proto-história dos laços entre imprensa de massa, literatura e política no romantismo. Serão, a seguir, apresentadas as revistas literárias que acolheram os autores da "grande geração romântica" e também os pequenos românticos, ${ }^{7}$ seu posicionamento político e as escolhas estéticas que propõem a seu leitor assim como a nova força enunciativa da ilustração, nestas revistas.

MAINGUENEAU, Dominique. Le discours littéraire; paratopie et scène d'énonciation. Paris: Armand Colin, 2004. (Discurso literário. Trad. Adail Sobral. São Paulo: Contexto, 2006). BOURDIEU, Pierre. Les règles de l'art; genèse et structure du champ littéraire. Paris: Seuil, 1992.

JUCAULT, Michel. L'archéologie du savoir. Paris: Gallimard, 1969

MELLO, Celina Maria Moreira de. O espetáculo está na sala. Recorte Revista de Linguagem, Cultura e Discurso. Ano 2, n. 2, janeiro a junho de 2005. UNINCOR, Três Corações, <http://www.unincor.br/recorte/>.

5 Apresento, neste ensaio, resultados parciais do projeto Crítica literária, política e revolução estética em L'Artiste 1831-8, desenvolvido de 2006 a 2009, com apoio do CNPq.

6 Era chamado folhetim o artigo de crítica literária, filosófica ou científica, regularmente publicado nos jornais, geralmente no rodapé da página.

7 BÉNICHOU, Paul. Le sacre de l'écrivain. Paris: Gallimard, 1996. 


\section{O jornalismo político e o folhetim}

Em 4 de agosto de 1789, quando são abolidos pelos revolucionários todos os privilégios feudais, eliminam-se de roldão as corporações de ofício, ou seja, no que se refere ao mundo da impressão, o privilégio de imprimir, o qual, no Antigo Regime, era um monopólio dos livreiros-impressores, os editores. Imprimir passa a ser uma atividade livre, de que se ocuparão donos de livrarias, vendedores de livros, redatores, jornalistas e tipógrafos, o que faz explodir o número de editoras e tipografias: "Na capital [Paris], ao final do Antigo Regime, havia, oficialmente, trinta e seis tipografias, que passam a ser quarenta e sete entre 1789 e 1790 e mais de duzentas e vinte, em $1798^{\prime \prime}{ }^{8}$ A Revolução Francesa trará uma vivência do impresso, ligada ao impacto político da leitura coletiva de textos em voz alta, nas ruas, nos clubes ou seções revolucionárias e nas casernas. Mas tal leitura não privilegia o livro: as folhas ou jornais multiplicam-se, de acordo com as mais diversas tendências políticas, veículos de propaganda dos ideais revolucionários: "Os títulos dialogam entre si, nascem e desaparecem também rapidamente: à sua volta forma-se uma comunidade de leituras que corresponde, aproximadamente, a uma comunidade de opinião". 9

Quantidade de periódicos publicados, na França, por ano: ${ }^{10}$

\begin{tabular}{c|c|c|c|c|c|c|c|c|c|c|c}
$\mathbf{1 7 8 9}$ & $\mathbf{1 7 9 0}$ & $\mathbf{1 7 9 1}$ & $\mathbf{1 7 9 2}$ & $\mathbf{1 7 9 3}$ & $\mathbf{1 7 9 4}$ & $\mathbf{1 7 9 5}$ & $\mathbf{1 7 9 6}$ & $\mathbf{1 7 9 7}$ & $\mathbf{1 7 9 8}$ & $\mathbf{1 7 9 9}$ & $\mathbf{1 8 0 0}$ \\
\hline 218 & 387 & 280 & 245 & 144 & 129 & 159 & 124 & 214 & 136 & 110 & 75
\end{tabular}

O impacto do periódico impresso mantém especialmente atenta a censura política revolucionária, o que confere ao folhetim e, sobretudo, à crítica literária, os quais escapavam da censura, uma dimensão cada vez mais ampla.

A relação entre folhetim, crítica literária e política se ilumina em um breve histórico dos primeiros anos do Journal des Débats. Folha criada em 1789, o jornal detinha um grande número de assinantes e, em 1799, muda de direção, passando à propriedade dos irmãos Bertin. Favorecido pelo retorno à ordem pública que foi o Diretório, passa a ser o porta-voz da reação social e religiosa aos excessos revolucionários do

BARBIER, Frédéric. L'histoire du livre. Paris: Armand Colin, 2000, p. 195. T. da A., exceto quando explicitamente referido.

9 Idem

10 Idem.

146 - MELLO, Celina Maria Moreira de. As revistas literárias no romantismo francês 
período chamado de Terror (1793-4). A crítica de teatro, que era publicada no folhetim, é assumida, então, por Julien-Louis Geoffroy (1743-1814), um erudito professor monarquista. Graças a seu talento, a seção passa a tratar também dos mais variados temas: literatura moderna, antiga, história, filosofia, moral e política.

A liberdade que não mais existia para a imprensa, na parte política propriamente dita, a liberdade que não existia no primeiro andar do jornal, desculpem a expressão, refugiou-se no térreo de Geoffroy. De lá ela disse tudo o que quis dizer, tudo o que era preciso dizer. É a esta situação que devemos atribuir a mistura de ideias literárias e políticas, esta colorida mistura de gêneros, que teria sido um defeito se não tivesse resultado de uma necessidade. Os folhetins de Geoffroy pareceram um pouco com aquelas igrejas da Idade Média que tinham direito de asilo e onde podiam se encontrar todos aqueles que não se podiam mostrar em outros lugares. ${ }^{11}$

O folhetim torna-se um sucesso, por publicar, com certa liberdade, críticas aos valores da Revolução Francesa e celebrar a volta à moral cristã. A crítica literária confunde-se, então, cada vez mais com a crítica política. No combate para restabelecer a importância de autores do século XVII e se opor a Voltaire, a pena de Geoffroy será comparada a uma espada. ${ }^{12}$ As referências literárias são alusões, apreciadas pelos leitores, aos acontecimentos políticos da atualidade, como no episódio do assassinato do duque de Enghien. ${ }^{13}$ Embora apoie Napoleão Imperador, o periódico é criticado por grupos de opiniões contrárias - filósofos e jacobinos - e seu sucesso comercial suscita a cobiça de seus inimigos. Assim, quando o jornal é visto como uma ameaça política, Napoleão, em 1805, lhe impõe primeiro um censor, depois um diretor de sua confiança, Joseph Fiévée (1767-1839), e finalmente a mudança do nome do periódico para Journal de l'Empire. $\mathbf{O}$ folhetim de Geoffroy e os artigos literários, contudo, continuam a escapar à censura, e a discussão de temas morais e literários continua a servir de pretexto para a exposição de pontos de vista políticos. ${ }^{14}$ Esta fase de liberdade relativa do jornal encerra-se, em 1807, quando Fiévée é substituído pelo dramaturgo Charles-Guillaume Étienne (1778-1845) e rompe-se o frágil equilíbrio entre revolucionários e monarquistas.

NETTEMENT, Alfred. Histoire politique, anecdotique et littéraire du Journal des Débats. v. 2. Paris: Dentu, 1842, p. 100-1.

12 Idem, p. 102-8.

13 Idem, p. 140-2.

14 Idem, p. 173.

Teresa revista de Literatura Brasileira [12|13]; São Paulo, p. 144-159, 2013 • 147 
Tendo [Napoleão] perdido a esperança de alcançar [este equilíbrio], ele fazia entrar os dois [espírito revolucionário e espírito monarquista] ao mesmo tempo, no Journal de l'Empire, símbolo da impraticável fusão que ele almejava realizar e desta união que ele desejava criar em proveito próprio, juntando os dois contrastes. De um lado o senhor Étienne e o senhor Tissot, que muito rapidamente foi publicado no Journal de l'Empire, representavam a nuance filosófica; do outro, Geoffroy, o senhor Feletz e Hoffmann, a quem haviam deixado sua independência literária, representavam o matiz monárquico religioso. ${ }^{15}$

Mas o folhetim continua a ser uma seção privilegiada em face da censura, o interesse pelos debates literários torna-se cada vez maior e o número de leitores aumenta. Em 1808, o jornal tem 20 mil assinantes. ${ }^{16}$ Uma vez que a censura é cada vez mais atuante no que se refere aos temas políticos, é exatamente o folhetim que atrai os leitores, por sua liberdade e pelo brilho de seus articulistas: "Napoleão havia dito: 'Deixemos que tenham a república das letras'; foi nessa república que o Journal de l'Empire se refugiou". ${ }^{17}$

Com a Restauração da monarquia, em uma legislação mais liberal (1819 e 1828), firma-se, para o governante, o princípio de conceder certa liberdade ao folhetim e aos artigos que tratam de literatura e, para os periódicos, a estratégia de se apresentarem como literários, para escapar à censura. ${ }^{18}$ Nos anos 1828 -9, assiste-se à criação de várias revistas "literárias", diretamente envolvidas nos debates políticos e estéticos de seu tempo. O movimento se acentua após a Revolução de Julho de 1830, que instaura uma monarquia constitucional e gera, em um primeiro momento, ampla liberdade de imprensa.

\section{As revistas literárias}

Um mapeamento das configurações do campo literário, na França, entre 1830 e 1840, em sua relação com o campo político, identifica a constituição de grupos distintos de escritores e artistas, com tendências políticas conflitantes: ultramonarquistas ou

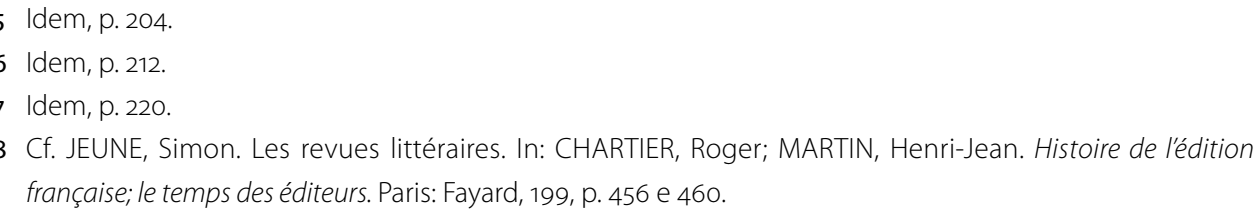


legitimistas, opondo-se tanto aos liberais, a favor de uma monarquia constitucional de acordo com o modelo inglês, quanto aos republicanos, fiéis aos ideais revolucionários. A sociabilidade parisiense distribui os diversos grupos pela capital francesa, nos diferentes bairros e salões. Conforme seu ideário político, estes grupos compartilham preferências estéticas diversas e formam o público leitor de diferentes revistas literárias. A primeira dificuldade com que nos defrontamos para avaliar a presença destas revistas no campo literário é a de definir revistas literárias. A segunda, que com aquela se relaciona diretamente, é a de definir literário. De acordo com um prospecto anônimo publicado em 1832, na Revue des Deux Mondes, atribuído a Sainte-Beuve (1804-69), o conceito de revista literária viria da Inglaterra e pressupõe um "método de pensamento e de ensino, que participa ao mesmo tempo do caráter atual do jornal e da discussão grave dos livros".19

Os pesquisadores do projeto Periódicos Literários: publicações efêmeras, memória permanente, da Fundação Biblioteca Nacional, contornam a dificuldade deslocando-a para a definição de literário: ${ }^{20}$

O projeto Periódicos Literários: publicações efêmeras, memória permanente realiza uma busca e uma indexação mais específica, a partir de um conceito que inclui na categoria de periódicos literários todos aqueles que contenham em sua pauta assuntos literários, de maneira exclusiva ou não: poesias e narrativas, textos informativos de crítica e debate. ${ }^{21}$

A solução é pragmática, uma vez que parte das práticas editoriais, considerando literário o que se autorreferencia enquanto tal. Contudo, com tal solução, corre-se o risco de se ver a literatura como um conjunto fechado e estável de textos, um universo estático, e deixar de perceber que se trata de um conjunto que se conforma incessantemente, no tempo, na tensão constante e nas disputas de grupos por uma posição de hegemonia e que faz parte destas disputas a luta pela inclusão ou exclu-

Idem, p. 455. A íntegra do prospecto pode ser consultada em Prospectus abonnement; Revue des Deux Mondes, t. 5, 1832, <http://fr.wikisource.org/wiki/Prospectus,_abonnement>, consultado em 28 dez. 2009.

20 Pesquisa realizada com o acervo da Coordenadoria de Publicações Seriadas/COPER, da Fundação Biblioteca Nacional/FBN, voltada para o tratamento bibliográfico de publicações periódicas e suas relações com o campo literário brasileiro. Cf. CORRÊA, Irineu Eduardo Jones. Periódicos Literários: publicações efêmeras, memória permanente, <http://www.letras.ufrj.br/prisma/projetos.htm>, consultado em 28 jan. 2009.

COSTA, Maria Ione Caser da; SILVA, Maria do Sameiro Fangueiro da. O acervo de periódicos literários da Fundação Biblioteca Nacional. In: CATHARINA, Pedro Paulo Garcia; MELLO, Celina Maria Moreira de. Cenas da literatura moderna. CD-ROM. Rio de Janeiro: Sete Letras, no prelo.

Teresa revista de Literatura Brasileira [12|13]; São Paulo, p. 144-159, 2013 • 149 
são, no cânone, de determinados gêneros e obras. Pois o que chamamos de discurso literário resulta destes processos, ou seja, de uma construção histórica. ${ }^{22}$

A Monarquia de Julho, que vem no bojo de uma revolução deflagrada por um movimento de defesa da liberdade de imprensa, vê o florescimento de inúmeras revistas de cultura, de informação geral e de debate de ideias, articulado com discussões estéticas e artigos de crítica literária, que são entremeados com a publicação de contos, poemas e capítulos de romances. Na rivalidade entre as revistas e em suas escolhas estéticas, ou nos gêneros que privilegiam, é tecido um complexo jogo de lutas simbólicas para deter o poder de definir o literário, preso entre a prosa e a poesia, os gêneros sublimes e as preferências do público, a tradição e o novo.

Com o intuito de ilustrar a diversidade social, política, econômica e estética desse amplo espectro, são destacadas quatro revistas: La Mode, Revue des Deux Mondes, LAArtiste e Musée des Familles, relacionadas com o mapa da sociabilidade parisiense:

\begin{tabular}{|c|c|c|c|c|}
\hline GRUPO SOCIAL & $\begin{array}{l}\text { aristocracia } \\
\leq 1830 \text {, pessoas } \\
\text { apresentadas ao } \\
\text { rei, corte } \\
\geq 1830 \text {, pessoas } \\
\text { que se retiraram } \\
\text { da corte }\end{array}$ & $\begin{array}{l}\text { aristocracia } \\
\text { alta burguesia } \\
\text { liberal do século } \\
\text { XVIII } \\
\text { estrangeiros } \\
\text { embaixadores }\end{array}$ & $\begin{array}{l}\text { banqueiros } \\
\text { homens de } \\
\text { negócios } \\
\text { políticos } \\
\text { artistas } \\
\text { jovens dândis }\end{array}$ & $\begin{array}{l}\text { burguesia } \\
\text { econômica, } \\
\text { quadros médios } \\
\text { funcionalismo } \\
\text { público, } \\
\text { comerciantes }\end{array}$ \\
\hline BAIRRO DE PARIS & $\begin{array}{l}\text { Faubourg St. } \\
\text { Germain }\end{array}$ & $\begin{array}{l}\text { Faubourg St. } \\
\text { Honoré }\end{array}$ & Chaussée d'Antin & Marais \\
\hline LINHA POLÍTICA & $\begin{array}{l}\text { legitimista: } \\
\text { apoia o ramo dos } \\
\text { Bourbon }\end{array}$ & $\begin{array}{l}\text { bonapartista } \\
\text { liberal: apoia a } \\
\text { Monarquia de } \\
\text { Julho }\end{array}$ & liberal & \\
\hline $\begin{array}{l}\text { VALORES } \\
\text { ESTÉTICOS E } \\
\text { FORÇA SOCIAL }\end{array}$ & $\begin{array}{l}\text { Rococó, } \\
\text { legitimação }\end{array}$ & $\begin{array}{l}\text { Luzes, } \\
\text { classicismo }\end{array}$ & $\begin{array}{l}\text { Romantismo, } \\
\text { poder e moda }\end{array}$ & $\begin{array}{l}\text { Imitação de valores } \\
\text { legitimados }\end{array}$ \\
\hline JORNAL & $\begin{array}{l}\text { Le Drapeau Blanc } \\
\text { Le Conservateur } \\
\text { La Gazette de } \\
\text { France } \\
\text { La Quotidienne }\end{array}$ & $\begin{array}{l}\text { Le Constitutionnel } \\
\text { Journal des Débats }\end{array}$ & Le National & $\begin{array}{l}\text { Le Siècle } \\
\text { La Presse }\end{array}$ \\
\hline
\end{tabular}




\begin{tabular}{l|l|l|l|l}
\hline REVISTA & LaMode & $\begin{array}{l}\text { La Minerve } \\
\text { Revue des Deux } \\
\text { Mondes }\end{array}$ & $\begin{array}{l}\text { Revue de Paris } \\
\text { L'Artiste }\end{array}$ & $\begin{array}{l}\text { Le Magasin } \\
\text { pittoresque } \\
\text { Musée des Familles }\end{array}$ \\
\hline
\end{tabular}

La Mode é uma revista fundada em 1829 por Émile de Girardin (1806-81), ${ }^{23}$ e adquirida em junho de 1831 pelos senhores Dufougerais e de Bermond, que será publicada até 1855. Era um luxuoso semanário, com tipos legíveis e papel de ótima qualidade, publicado todo sábado, em cadernos de 24 páginas. Contava, em junho de 1830, com uma tiragem de 2.625 exemplares. ${ }^{24}$

Em seus primeiros anos, não foi um periódico com teor político. ${ }^{25}$ Revista da corte, dirigida a um público de elite, oferecia a seus exigentes leitores estampas das toaletes das damas mais elegantes: "A grande questão na ordem do dia, nos boudoirs de nossos elegantes de 1828, eram o corte, a forma, os matizes, o volume mais amplo ou mais reduzido de suas vestimentas". ${ }^{26}$ As gravuras de La Mode, litografias coloridas a partir de 1831, permitem reconstituir a originalidade e a fantasia dos vestidos, das mangas, dos turbantes, inspirados por sua protetora e musa, Maria Carolina de Bourbon (1798-1870), duquesa de Berry e nora do rei Carlos x (1757-1836). Os homens têm como grande modelo o rei Carlos x: "[...] desde os primeiros dias de sua existência, ela refletiu, até certo ponto, as tendências elegantes e aristocráticas da mais refinada sociedade europeia daquela época, personificada na corte do rei Carlos x". ${ }^{27}$

Esta revista de moda diferencia-se de suas concorrentes por "abrir novos horizontes à literatura" e trazer escritores da Escola nova ou Escola jovem: Delphine Gay (mais tarde senhora Émile de Girardin, 1804-55), Charles Nodier (1780-1844), Eugène Sue (1804-57), Jules Janin (1804-74), que assina o primeiro artigo sobre moda da revista, Honoré de Balzac (1799-1850) e Victor Hugo (1802-85).$^{28}$ Embora publique alguns contos ou narrativas destes autores, o destaque maior é dado à poesia. No que se refere ao sucesso de escândalo do drama romântico Hernani (Victor Hugo, 1830),

Este se tornará em pouco tempo um dos maiores empresários da imprensa e, na história da literatura francesa, terá seu nome associado ao gênero do romance de folhetim.

24 BARBAT de BIGNICOURT, Arthur. Histoire du journal La Mode par le Vte E. de Grenville. Paris: Bureau de "La Mode nouvelle", 1861, p. 13.

25 Idem.

26 Idem, p. 15.

27 Idem, p. 13

28 Cf. BARBAT de BIGNICOURT, Arthur. Histoire du journal La Mode par le Vte E. de Grenville. Op. cit., p. 13. 
que não pode ser separado nem dos temas da moda, nem da agitação do período pré-revolucionário, ${ }^{29}$ a revista publicará uma crítica ironicamente negativa:

Os jornais e o pequeno grupo que se intitulou a Nova escola fizeram muito barulho sobre a representação de Hernani, drama vulgar e enfático, que não conseguiu tocar a imobilidade dos salões: La Mode vai imitar os salões, ela não se ocupará deste drama, contra o qual o público pode finalmente protestar por ocasião da terceira representação que, na verdade, era a primeira. Já se ouve falar de vinte e quatro paródias de Hernani, a melhor será o manuscrito impresso. ${ }^{30}$

La Mode desaprova a Revolução de Julho de 1830 e a mudança de regime, que coloca no trono Luís Filipe de Orléans (1773-1850), um rei que parece um burguês. A revista se tornará "o grande órgão de oposição legitimista à Monarquia de Julho".31

A Revue des Deux Mondes, fundada igualmente em 1829, ${ }^{32}$ por Prosper Mauroy e Ségur-Dupeyron, é adquirida em 1831, por Auguste Auffray que entrega sua direção a François Buloz (1803-77), que a dirigiu até sua morte. ${ }^{33} \mathrm{~A}$ revista seguia o modelo inglês dos magazines, o que aparece claramente em seu subtítulo: recueil de la politique, de l'administration et des moeurs (coletânea da política, da administração e dos costumes). Caracterizava-a uma ênfase maior dada aos artigos de informação histórica e geográfica, relacionada com a literatura de viagem. Visava a favorecer as relações culturais, políticas e, sobretudo, econômicas entre o Velho e o Novo Mundo, ou seja, a Europa, tomando como parâmetro a França e a América, o que atendia às demandas de um leitor burguês, que ela define como "aristocrático". Sua linha política é liberal: no período que antecede a Revolução de 1830, representara uma oposição moderada ao regime de Carlos $\mathrm{x}$.

Em 1833, Buloz adquire a rival Revue de Paris e faz da Revue des Deux Mondes a mais importante das revistas literárias no período da Monarquia de Julho, acolhendo em

Cf. MELLO, Celina Maria Moreira de. O espetáculo está na sala. Recorte Revista de Linguagem, Cultura e Discurso. Op. cit.

30 Transcrição de um artigo de La Mode, datado de janeiro-fevereiro de 1830. Cf. BARBAT de BIGNICOURT, Arthur. Histoire du journal La Mode par le Vte E. de Grenville. Op. cit., p. 44.

31 WATELET, Jean. La presse illustrée. In: CHARTIER, Roger; MARTIN, Henri-Jean. Histoire de l'édition française; le temps des éditeurs. Op. cit., p. 370.

32 A revista é publicada até hoje e tem um site oficial: <http://www.revuedesdeuxmondes.fr>

33 Em 1833, Buloz compra a revista. Cf. CAMARGO, Katia Aily Franco de. A Revue des Deux Mondes; intermediária entre dois mundos. Natal: EDUFRN, 2007, p. 37-43

152 - MELLO, Celina Maria Moreira de. As revistas literárias no romantismo francês 
suas páginas autores como François-René de Chateaubriand (1768-1848), George Sand (1804-76), Alfred de Vigny (1797-1863), Alfred de Musset (1810-57), Heinrich Heine (1797-1856), Alexandre Dumas (1802-70), Théophile Gautier (1811-72) e, muitos anos mais tarde, Charles Baudelaire (1821-67).

Publicação mensal, continha de sete a oito fólios - entre 112 e 128 páginas - que seriam reunidos em quatro volumes por ano. $\mathrm{O}$ custo da assinatura anual, no momento de seu lançamento, era de quarenta francos para Paris, 45 para a província e cinquenta francos para o exterior. ${ }^{34}$ De formato in-oitavo e máscara gráfica ${ }^{35}$ mais sóbria, não fazia concessões aos exageros românticos, tampouco cedia ao gosto imoderado do público por imagens.

Suas tendências eram mais clássicas. Entre seus principais críticos de arte e literatura, Étienne-Jean Delécluze (1781-1863), davidiano pouco entusiasmado pela nova estética e defensor dos valores republicanos do neoclassicismo. Também devem ser citados Gustave Planche (1808-57), um dos críticos mais ferozes do romantismo, totalmente hugofóbico e defensor da tradição clássica, e Sainte-Beuve, extremamente reticente em relação ao que ele denomina "a invasão da democracia literária": massificação da literatura (literatura industrial), não especialização dos críticos e escritores e, sobretudo, a voga do romance de folhetim. ${ }^{36}$

A Revue des Deux Mondes aliás é muito interessante, na perspectiva que nos interessa, pois ela se apresenta como um espaço em que se encontram - um dos últimos - a literatura romântica e a literatura acadêmica (ensaios críticos, históricos, políticos, arqueológicos) entre o mundo da cultura oficial e esse outro mundo que está a seu lado, o ultrapassa e dele está se afastando.37

L'Artiste, journal de la littérature et des beaux-arts, fundada logo após a Revolução de 1830, por Achille Ricourt (1776-1865), rico amador de arte, apoiava claramente o regime da Monarquia de Julho. Publicada até 1904, ao longo de sua existência a

34 A diária de um bom operário era, naquela época, de 3,50 francos. Cf. CRUBELLIER, Maurice. Lélargissement du public. In: CHARTIER, Roger; MARTIN, Henri-Jean. Histoire de l'édition française; le temps des éditeurs. Op. cit., p. 31.

35 Elementos visuais, fonte, paginação, vinhetas, ilustrações que integram o projeto gráfico da revista e compõem seu ethos editorial, em uma projeção impressa de valores.

36 SAINTE-BEUVE. De la littérature industrielle. In: DUMASY, Lise. La querelle du roman-feuilleton. Grenoble: ELLUG, 1999 (Revue des Deux Mondes, $1^{\text {er }}$ septembre 1839), p. 25-43.

37 DUMASY, Lise. La querelle du roman-feuilleton. Grenoble: ELLUG, 1999, p. 11.

Teresa revista de Literatura Brasileira [12|13]; São Paulo, p. 144-159, 2013 • 153 
revista mudou diversas vezes de proprietário, editor e formato. Publicação semanal, cara e luxuosa, voltada para um leitor artista ou amador de arte, diferenciava-se de suas rivais pela ênfase dada às Belas-Artes, com uma política de "fraternidade das artes" e pelo amplo uso da ilustração. ${ }^{38} \mathrm{Um}$ uso recorrente de xilogravuras e gravuras destacáveis acompanhavam o fascículo semanal.

O grupo de artistas e escritores que publica confunde-se com o grupo do salão do Arsenal, que se reúne em torno de Charles Nodier e é o único salão que acolhe, incondicionalmente, os defensores do novo regime e da nova estética. Pois a sociedade parisiense desaprova, em seu conjunto, o novo regime e os salões se fecham, de início, para seus defensores e simpatizantes. ${ }^{39}$

Muito significativamente, o editorial de seu primeiro número - Etre artiste - vem assinado pelo escritor e crítico Jules Janin, folhetinista do já citado Journal des Débats, que fizera oposição ao regime de Carlos $\mathrm{x}$ e que, àquela época, foi considerado o verdadeiro órgão da Monarquia de Julho. ${ }^{40}$ A posição política e o posicionamento estético de L’Artiste são, deste modo, os mesmos do Journal des Débats.

A revista rompe com certo equilíbrio simétrico entre duas posições opostas no campo político, associadas a dois posicionamentos estéticos contraditórios no campo literário: republicanos ou liberais, defensores da estética neoclássica, e ultramonarquistas, favoráveis ao romantismo. A revista abriga todas as tendências da nova estética, até mesmo a vertente frenética ligada aos pequenos românticos e repudiada pela Revue des Deux Mondes.

Todos os gêneros literários são, igualmente, acolhidos por L’Artiste, que se mostra aberta à experimentação estética, dando especial destaque às narrativas em prosa, fantásticas, históricas ou "realistas". ${ }^{41}$ Tais narrativas, com frequência, trazem à cena protagonistas artistas - pintores, escultores, músicos, poetas -, conferindo-lhes perante aquela sociedade burguesa um estatuto privilegiado. L'Artiste diferencia-se ainda das demais revistas literárias por um constante jogo de artigos críticos e alusões

38 MELLO, Celina Maria Moreira de. Crítica literária, política e revolução estética em L'Artiste 1831-1838. In: MELLO, Celina Maria Moreira de; CATHARINA, Pedro Paulo Garcia Ferreira. Crítica e movimentos estéticos; configurações discursivas do campo literário. Rio de Janeiro: 7Letras, 2006, p. 13-41.

39 DAMIRON, Susanne. Une grande revue d'art L'Artiste; son rôle dans le Mouvement artistique au XIXe siècle, ses illustrations hors-texte. 1831-56. Thèse complémentaire pour le Doctorat ès-lettres présentée à la Faculté des Lettres de l'Université de Paris. 1946 (exemplaire dactylographié).

40 Cf. L'Artiste, $1^{\text {ère }}$ série, tome I-II, 1831, disponível em <http://gallica.bnf.fr>.

41 Narrativas de ambientação urbana, cujas tramas são contemporâneas e envolvem personagens do povo ou da pequena burguesia. 
elogiosas cruzadas - chamado de camaraderie -, que assumem valor de reclame para artistas e escritores. As questões relativas à arte apresentam um viés político, quando se trata de discutir a escolha de júris de exposições e sua periodicidade, critérios de seleção em concorrências públicas ou premiações.

Criada em 1833, igualmente por Émile de Girardin, Musée des Familles, lectures du soir foi apresentada como uma revista completa, possuindo qualidade comparável aos grandes periódicos ingleses. ${ }^{42}$ Trazia a arte, que era um luxo aristocrático, às camadas mais simples da sociedade, traduzindo-a de maneira familiar, no intuito de tocar todos. Não só a arte, mas também a literatura, a história, a botânica, a geografia, a moda, narrativas de viagens, costumes e temas militares, juntamente com um amplo uso de imagens. Tinha a proposta de uma literatura divertida e útil, ou seja, de alto interesse, instrutiva e moral. O subtítulo da revista indica um público popular ou da pequena burguesia, o da família que se reúne após o jantar, em torno de uma única lâmpada, para leituras do serão. O conteúdo da revista não devia chocar os valores morais da família cristã, das mulheres casadas ou solteiras nem das crianças.

O Musée des Familles apresentava-se com o formato de um fascículo, disponível todo dia 20 de cada mês; os números do primeiro volume (de outubro de 1833 a setembro de 1834) foram publicados no dia 25 . O volume continha doze números anuais de 32 páginas mensais cada. A assinatura poderia ser mensal, custando 25 centavos na sede do jornal ou setenta centavos pelo correio, ou anual, custando 5,20 francos na sede do jornal ou 7,20 francos pelo correio.

A liberalidade política do novo regime monárquico constitucional vai aproximadamente até 1835 , quando a censura retorna mais atenta aos periódicos que se multiplicam, favorecidos pelos avanços técnicos de impressão, com tiragens maiores e a reprodução mecânica de imagens. Modernizam-se as técnicas de impressão, difusão e circulação do impresso; jornais e revistas aumentam em um ritmo acelerado, ampliando-se a massa de leitores urbanos.

Estas e as demais informações referentes ao Musée des Familles encontram-se consignadas no relatório de pesquisa da aluna de Iniciação Científica Vaneska Cristina Prates da Silva Mariano, que desenvolveu, em 2006, com minha orientação, junto ao PPG Letras Neolatinas/UFRJ, o projeto A iconografia e o ethos no Musée des Familles (de 1833 a 1839). 


\section{A ilustração romântica}

Em torno do periódico reúne-se uma comunidade de opinião, cuja opção política e gosto estético são por ele conduzidos. Objeto cultural de dimensões complexas, a revista literária constitui um espaço de enunciação em contínua tensão, na disputa de grupos por hegemonia no campo político, literário e artístico. Seus articulistas, os editoriais e os autores que publicam em suas páginas associam-se com sua máscara gráfica, para constituir um espaço de enunciação diversificado, mas coeso.

A ilustração, no periódico literário, assume um lugar de destaque. Nos anos 1820-30, há três técnicas de impressão de gravuras: a calcografia, cuja matriz é uma chapa de metal; a litografia, cuja matriz é uma placa de pedra desenhada com lápis gorduroso ou com tinta oleosa; e a xilografia de topo, técnica importada da Inglaterra por volta de 1820, em que a madeira é cortada no sentido transversal ao tronco original e permite imprimir, na mesma página, texto e ilustrações. ${ }^{43}$

A calcografia é um processo caro e limitado a imagens destacáveis (hors texte). A técnica da litografia, de execução mais fácil, é igualmente limitada a tiragens pequenas de imagens destacáveis, para que se possa conservar a nitidez do desenho. Foi muito usada pelos jornais de moda e nas caricaturas. A xilografia de topo, de início, servia apenas para preencher partes de páginas em branco, nos finais de capítulos os chamados fundos de lâmpada.

Rapidamente, por seu baixo custo e pela qualidade de imagem que faculta seu aperfeiçoamento técnico, juntamente com a possibilidade de imprimir uma ilustração contígua a um texto ou nele inserida, esse tipo de ilustração será encontrado em frontispícios de livros e jornais, vinhetas de título/vinhetas de cabeçalho, ornatos marginais, letras capitulares, fundos de lâmpada, vinhetas inseridas no texto ou até mesmo em páginas destacadas. A xilografia de topo renovará os temas da literatura romântica e aproximará os leitores do texto impresso, tornando-se marca estética de jornais, revistas e livros.

A imprensa jornalística serve-se deste recurso, em vinhetas de cabeçalho de caráter ornamental e publicitário, muito apreciadas pelo leitor e que assumem o valor de uma identificação enunciativa. Henri Béraldi considera que a vinheta de título de La Mode constitui um marco da renovação da arte da gravura. ${ }^{44}$ Aliás, é La Mode

Cf. MARCONDES, Luiz Fernando. Dicionário de termos artísticos; com equivalências em inglês, espanhol e francês. Rio de Janeiro: Pinakotheke, 1998.

44 Cf. BÉRALDI, Henri. Les graveurs du XIXe siècle; guide de l'amateur d'estampes modernes, vol. VIII. Paris: L. Conquet, 1889, p. 251.

156 MELLO, Celina Maria Moreira de. As revistas literárias no romantismo francês 
que publica a primeira litografia: Traineau attelé à la Moscovite. ${ }^{45}$ Para Aristide Marie, destacam-se as vinhetas da Revue des Deux Mondes e da revista L'Artiste, de fevereiro de 1831, ambas de autoria de Tony Johannot (1803-52):

Podemos imaginar que a Revue des Deux Mondes seja publicada, em julho de 1830, sedutoramente enfeitada com um desenho de Tony Johannot? É verdade que a revista ainda não é o austero volume em que se transformará mais tarde: o lápis de Tony associa-se com bastante propriedade aos artigos de Nodier, Balzac, Dumas, Janin, Paul Foucher e Émile Deschamps. Mas quando essa revista tiver adotado, definitivamente, seu aspecto doutrinário, as duas delicadas figuras femininas - uma delas audaciosamente despida - que aparecem na Deux Mondes, serão, sem perdão, eliminadas da capa. Do mesmo modo, Ricourt solicita ao gentil mestre que desenhe uma vinheta para o título de L'Artiste, quando é fundada, em 1831, essa luxuosa revista de arte..$^{46}$

A vinheta de cabeçalho deve atrair a atenção do leitor e projetar a representação figurativa de seus valores políticos e estéticos. A vinheta de La Mode indica, pela delicadeza do traço e o requinte da profusão de detalhes, o gosto estético exigido por um leitor de elite, que vê a corte como um modelo. A austera Revue des Deux Mondes elimina uma sensual vinheta de cabeçalho, incompatível com a imagem de seriedade que almeja e cuja assinatura, a de Tony Johannot, associa-se ao romantismo de Charles Nodier e ao já citado salão do Arsenal. A vinheta de cabeçalho de L'Artiste é uma alegoria da Literatura e das Artes, representadas por jovens vestidos à moda contemporânea e não como figuras da tradição mitológica, celebrada pelo neoclassicismo: trata-se de firmar uma declaração de modernidade.

O Musée des Familles, cujo leitor é menos abonado, faz questão de explicitar que terá a mesma qualidade de impressão, seus artigos e gravuras serão assinados pelos mais prestigiosos artistas:

A colaboração dos escritores e dos artistas de elite não é aqui um mero ornamento de prospecto, como em tantos jornais que se enfeitam dos mais belos nomes sem se

45 Cf. WATELET, Jean. La presse illustrée. In: CHARTIER, Roger; MARTIN, Henri-Jean. Histoire de l'édition française; le temps des éditeurs. Op. cit., p. 370.

46 MARIE. Alfred et Tony Johannot. Paris: H. Floury, 1925, p. 30-1.

Teresa revista de Literatura Brasileira [12|13]; São Paulo, p. 144-159, 2013 • 157 
enriquecer de seus trabalhos; todas estas assinaturas figuram na coleção do Musée des Familles e nela continuarão a figurar abaixo dos artigos e das gravuras mais notáveis. ${ }^{47}$

O traço, contudo, será mais simples, atendendo a objetivos didáticos.

A ilustração contribui para o sucesso comercial das revistas e não mais se limita a ser porta-voz de uma posição política ou o espaço que acolhe a divulgação de posicionamentos estéticos, mas torna-se, igualmente, um poderoso recurso para a instrumentalização pedagógica da imprensa. Trata-se de se colocar a serviço da educação literária, e artística, assim como de veicular valores morais, visando a uma massa ainda não representada pelas instituições políticas, mas que constitui a poderosa opinião pública. A imagem, que pode ser encontrada ao longo da publicação, associa-se ao texto poético, de teatro ou de ficção narrativa, na crítica da sociedade regida por um jogo político que é controlado pelas elites, ou seja, a alta burguesia.

Além de integrar o título da revista, na forma de uma vinheta de cabeçalho, a xilogravura de topo pode ser encontrada, nos periódicos, em fundos de lâmpada ou como ilustração acompanhando poemas, narrativas ou resenhas críticas de romances ou coletâneas de contos, com uma verdadeira função de reclame. ${ }^{48}$ Do mesmo modo que certos autores e críticos do romantismo circulam pelas revistas, os mesmos desenhistas e gravadores podem assinar suas ilustrações.

0 recurso insistente às imagens, nas revistas literárias, insere-se no mesmo movimento de popularização da literatura dramática sublime, que busca renovar cenários, figurinos e jogos cenográficos inspirando-se na pintura e em gravuras de temas históricos. Igualmente não pode ser dissociada da ascensão do romance, que o levará a ser o gênero/formato literário dominante. Este aumenta suas tiragens, barateia seus custos e busca o lucro, atento ao gosto do público, trazendo nas capas vinhetas de título e fazendo um uso cada vez maior de ilustrações.

47 Musée des Familles, t. 5, 1847-8 : folha de rosto, verso, disponível em <http://gallica.bnf.fr>.

48 Cf. MELLO, Celina Maria Moreira de. Crítica literária, política e revolução estética em L'Artiste 1831-8. In: MELLO, Celina Maria Moreira de; CATHARINA, Pedro Paulo Garcia Ferreira. Crítica e movimentos estéticos; configurações discursivas do campo literário. Op. cit. 


\section{Conclusão}

Algumas reflexões finais podem ser propostas à guisa de conclusão provisória. Sobre a dificuldade de se definir romântico, sem levar em conta a coexistência de estéticas conflitantes e rivais, associadas a valores sociais e programas políticos diversos. $\mathrm{O}$ amplo espectro de revistas literárias e as escolhas de autores, gêneros e tipos de ilustração muito devem às circunstâncias históricas e a certo oportunismo comercial. Por outro lado, a questão da ilustração, em suas relações com o literário, ainda não está resolvida. A forte presença de imagens e sua proximidade com o texto representam uma concorrência e uma aliança com o literário, comparável ao que ocorreu com a fotografia, o cinema, a televisão e, em nossos dias, com a imagem digital. Seu repúdio pela Revue des Deux Mondes e seu uso facilitador na Musée des Familles podem ser compreendidos à luz da tradição neoplatônica que faz da imagem uma cópia da cópia e confere ao texto mais prestígio, na clivagem atividade manual/ intelectual. Ou na tensão entre arte e literatura para as elites e arte e literatura para as massas. Nas revistas literárias do romantismo francês, a ilustração, que anos mais tarde Baudelaire chamará de "preciosos arquivos da vida civilizada",49 está longe de ter uma função acessória; sua função merece, pois, ainda ser redimensionada.

Celina Maria Moreira de Mello é professora de Língua e Literatura Francesa da UFRJ, onde atua no Programa de Pós-graduação em Letras Neolatinas. Pesquisadora do CNPq, desenvolve atualmente o projeto Do literário \& do prosaico; interrogações sobre o realismo, voltado para a leitura de traços da estética realista, em obras do romantismo francês, publicadas no período da Monarquia de Julho (1830-48). Publicou, entre outros ensaios, "La trágica soledad y el hacer poético en Marguerite Duras" (Revista Página Literal, École Lacanienne de Psychanalyse, Costa Rica, 2008), "Baudelaire e a poesia da cidade grande", Provocações da cidade (In: Guberman \& Pereira (org.), ufrJ, 2009) e "A Europa culta e o maravilhoso deserto" (O Eixo e a Roda, UFMG, 2009). 